\title{
Development of technology elements of original potato seed production based on microclonal reproduction
}

\author{
M.Yu. Karpukhin ${ }^{1, *}$, T.A. Artemyeva ${ }^{1,2}$, A.V. Belogurova ${ }^{2}, I . N . \mathrm{Krupsky}^{2}$, and E.M. \\ Yushkin $^{1}$ \\ ${ }^{1}$ Ural State Agrarian University, Yekaterinburg, Russia \\ ${ }^{2}$ LLC SSK Uralskiy Kartofel', Yekaterinburg, Russia
}

\begin{abstract}
The article describes the research results on the technology elements improvement of original potato seed production, which were carried out on the basis of the modern enterprise LLC SSK "Uralskiy Kartofel"' in a greenhouse complex for the cultivation of mini tubers. The influence of initial material's types of potatoes on the growth, development and yield of mini tubers in sheltered ground was studied as research objects. Experimental options' planting was carried out in the second rotation - July 30, 2020 according to the standard generally accepted technology. As a result of the studies, it was found that the best indicator was in the options where the source material was micro plants planted at the end of the phase of growth declining and the use of micro tubers providing a high yield of the standard fraction.
\end{abstract}

\section{Introduction}

Potatoes are one of the main crops that ensure the food security of our country. The universality of its use as a food, technical and foraging crop increases its strategic importance.

According to the numerous studies' results of domestic and foreign scientists, it was established that successful potatoes' cultivation depends on the correct selection of modern varieties, the quality of the applied planting material, scientifically based use of organic and mineral fertilizers, the use of crop rotations and effective control of weeds, pests and diseases. The role of the variety to produce a good harvest is constantly growing and ranges from 30 to $50 \%$. And it is very important to use high-quality planting material, which imposes high requirements for the seed production maintenance of this crop $[3,9,12]$.

Basically, potatoes reproduce vegetatively, which allows to preserve the original economic traits and properties of the varieties used. At the same time, with prolonged reproduction, there is an accumulation of various pathogens, especially viruses and bacteria, which are mostly impossible to cure. Therefore, the improvement of in vitro biotechnological methods' elements of potato reproduction and obtaining high quality

\footnotetext{
${ }^{*}$ Corresponding author: mkarpukhin@yandex.ru
} 
planting material, modern competitive domestic varieties free from viral and bacterial infection are of great practical importance for successful potato farming, improving yields, quality of products and production profitability.

Currently, technologies of accelerated seed production are widely studied not only in Russia, but also in other countries of the world. Test-tube micro-plants revitalized by apical meristem method serve as the source material in the production of original seeds. One such micro-plant can be divided into 3-8 stalks, which allows to get tens of thousands of new plants in a short time.

To date, micro-tubers are also used as the source material in addition to test-tube plants. Such tubers take up less space during storage, they are more convenient to transport, have higher productivity than in vitro plants in the production of mini tubers $[5,7]$.

The introduction of micro-tubers cultivation technology in the laboratory process contributes to year-round cultivation of in vitro material. The distribution of working time in the laboratory occurs evenly throughout the year. This technique can be used as a supplement to the clonal micropropagation program.

Objective of the study: to establish the influence of the potato raw material type on the growth, development, and yield of mini tubers of the Kolomba variety in sheltered ground.

Research objectives:

1) Determine the timing of basic phenophases' passage by potato plants depending on the type of source material.

2) To study biometric indicators in the studied options.

3) Determine the yield and fractional composition of the obtained mini tubers.

\section{Objects and methods of research}

The research was carried out in 2020 in the greenhouse complex of the breeding and seed company "Uralskiy Kartofel"'. It is one of the largest companies in Russia for diagnostics and production of original and elite seed potatoes. The company is one of the most modern seed centers by laboratory equipment.

According to GOST 33996-2016 "Seed potatoes. Technical conditions and methods of quality determination" - the source material is potatoes of a certain botanical variety, free from bacterial and viral infection, obtained by methods of biotechnology and selection. Such potatoes are designed to produce original seed material.

Original seed potatoes obtained during the breeding of the source material are intended to produce elite seed potatoes.

The source and original seed potato category includes source material (microplants, micro-tubers, mini tubers), the first field generation derived from mini tubers, and super super-elite seed potatoes $[2,13]$.

Micro-plants in in vitro culture should be green in color with a well-developed root system and leaf apparatus, with an internodes' number of not less than four [2, 10, 11].

According to the generally accepted assessment of morphogenesis of potato material in vitro, three phases of micro-plant development are distinguished. Phase of intensive growth includes the stages of germination and formation of 2-3 internodes. The phase of growth declining occurs when plants reach standard parameters - 4-6 internodes, it is quite long in duration. Its duration can be from 3 to 6 weeks. Physiological aging begins with the natural die-off phase of micro-plants. Depending on varietal features, micro-plants of potatoes reach a phase of growth declining in 21-35 days. In the Kolomba variety, this occurs in 25-28 days.

The object of the study are micro-plants and micro-tubers of potatoes of the Kolomba variety. 
Experimental options:

1) Micro tubers;

2) "Young" micro-plants (the period from grafting to planting 28-30 days, the beginning of the phase of growth declining);

3) "Old" micro-plants (the period from grafting to planting 50-55 days, the end of the phase of growth declining).

Standard "young" plants (28-30 days) were taken as control.

The Kolomba variety is a super-early variety of table purposes well adapted to various climatic conditions. The growing season is 55-60 days after sprouting. The maximum yield in Russia - $422 \mathrm{cwt} / \mathrm{ha}$. Starch content - $10.3-15.0 \%$. The pulp and peel are yellow in color. Weight of a commercial tuber - 82-132 g. Usual number of tubers per bush is 10-15 pcs. The variety has high resistance to potato wart disease, golden potato nematode, $\mathrm{Y}$ virus, buck eye rot, common scab; has an average resistance to buck eye rot of the tops $[4,6]$.

Cloning of test-tube plants is carried out on a nutrient medium with a mineral base according to Murashige and Skoog. After grafting, micro-plants are placed in a culture room with specified parameters of illumination, temperature and humidity. The process of tuber formation is influenced by varietal features of plants. Conditions have been developed for mass production of micro-tubers measuring $0.7-1.8 \mathrm{~cm}$ in diameter, which are suitable for growing in the soil. To initiate the stolons' formation, micro-plants are poured over with sugar solution and placed under the light mode for 5-6 days: 16 hours of darkness and 8 hours of light. Then they are put in the dark place for tubers' formation $[1,6]$. Most of the varieties form micro-tubers in a test tube for 55-60 days.

After reaching $0.7-1.8 \mathrm{~cm}$ of micro-tubers size, they are extracted from the tubes, washed with distilled water from agar, placed in containers and stored in the refrigerator at a temperature of $2-4{ }^{0} \mathrm{C}$. If necessary, the dormant period is interrupted artificially.

The in vitro material planting was carried out in the greenhouse complex in sheltered ground conditions in compliance with all parameters. Planting of experimental options was carried out in the second greenhouse rotation - 30.07.20. Micro-plants' planting was made according to the standard technology, and micro-tubers were laid to a depth of 1$2 \mathrm{~cm}$ in pots with peat with a volume of 5 liters. A dropper was installed in each pot, through which water and necessary nutrients were automatically supplied [5].

\section{Results and discussion}

Seasonal development of potato plants consists of morphological stages succeeding each other. A system of phenophases is used in phenological observations, which are presented in table 1 .

Table 1. Phenological observations.

\begin{tabular}{|c|c|c|c|}
\hline Observarions & $\begin{array}{c}\text { "Young" plants } \\
\text { (control) }\end{array}$ & "Old" plants & Micro-tubers \\
\hline Planting date & 30.07 .20 & 30.07 .20 & 30.07 .20 \\
\hline Sprouts & - & - & 12.08 .20 \\
\hline Flowering & 28.09 .20 & 28.09 .20 & - \\
\hline Ripening & 06.10 .20 & 06.10 .20 & 06.10 .20 \\
\hline Desiccation & 10.09 .20 & 10.09 .20 & 10.09 .20 \\
\hline Harvesting date & 14.10 .20 & 14.10 .20 & 14.10 .20 \\
\hline
\end{tabular}

In the potato production in two greenhouse rotations, the plants' growing season from the moment of planting to harvesting is an important factor. The growing period of "young" and "old" plants from planting to harvesting amounted to 77 days, and micro-tubers - only 63 days, with micro-tuber plants missing the flowering phase due to insolation deficiency in 
the autumn period. The process of germination and sprouting of micro-tubers took about 10-15 days in our experiment, while potato plants, the source material of which were micro-plants, already reached a height of $15-20 \mathrm{~cm}$ during this period of time. Further, when using micro-tubers as a source material, it is planned to adjust the preparation process of micro-tubers for planting and the process of planting in peat soil to reduce the growing period.

Biometric indicators - plant height, number of stems, number of leaves, which are shown in table 2, are believed to be significant traits determining the size of the potato harvest. Optimal photosynthetic surface ensures maximum accumulation of dry matter in the tubers.

Table 2. Biometric observations.

\begin{tabular}{|c|c|c|c|}
\hline \multirow{2}{*}{ Observarions } & \multicolumn{3}{|c|}{ Source material } \\
\cline { 2 - 4 } & $\begin{array}{c}\text { "Young" plants } \\
\text { (control) }\end{array}$ & "Old" plants & Micro-tubers \\
\hline Plant height, cm & 127.4 & 120.2 & 20.4 \\
\hline Number of stems, pcs. & 1.0 & 1.0 & 1.1 \\
\hline Number of leaves, pcs. & 13.1 & 13.1 & 6.8 \\
\hline
\end{tabular}

Biometric observations were carried out at a time when plants from "young" and "old" micro-plants reached the end of flowering phase. Biometric indicators in options where the source material was "young" and "old" plants did not differ significantly. Plants reached a height of 120-127 cm. Due to the protracted germination process and sprouting of microtubers, plants in this option were 6 times shorter than plants grown from micro-plants and had almost half as many leaves.

Potato harvesting and yield accounting were carried out on 14.10.20. To account for the harvest in each option, 20 plants were taken. The following parameters were considered: total number of tubers, total tuber weight, average weight of one tuber and average number of tubers per plant. The accounting data are shown in table 3.

Table 3. Yield accounting.

\begin{tabular}{|c|c|c|c|}
\hline Observarions & $\begin{array}{c}\text { "Young" plants } \\
\text { (control) }\end{array}$ & "Old" plants & Micro-tubers \\
\hline Number of plants, pcs. & 20 & 20 & 20 \\
\hline Number of tubers, pcs. & 93 & 143 & 118 \\
\hline Weight of tubers, kg & 2.5 & 2.6 & 2.0 \\
\hline $\begin{array}{c}\text { Average weight of one } \\
\text { tuber, g }\end{array}$ & 27 & 18 & 17 \\
\hline $\begin{array}{c}\text { Average number of } \\
\text { tubers per 1 plant, pcs. }\end{array}$ & 4.7 & 7.2 & 5.9 \\
\hline
\end{tabular}

Some authors believe that one plant derived from a micro-tuber is thought to form 10-16 tubers with a weight of 680-700 g. The height of plants derived from micro-tubers significantly differs from the height of micro-plants or from mini tubers. The difference in height is approximately $25-30 \%$ [5].

The table shows that the largest number of tubers was formed in the option with the source material being "old" micro-plants - 143 pcs, which is $17 \%$ more than the option with the "micro-tubers" source material and 35\% more than the option with the "young" plants source material. These proportions are also preserved when calculating the average number of tubers per plant. The maximum indicator was provided by "old" plants - 7.2 tubers. The total tubers' weight in the experiment was recorded to further calculate the weight of one tuber. The mass of the potato tuber is important for its storage and sprouting. Tubers with small weight tend to lose moisture rapidly after the dormant period and form a low stem 
number. Micro-tubers and "old" plants, which served as the source material, allowed to form mini tubers weighing 17-18 g. Potato plants from "young" micro-plants provided the yield of mini tubers with the highest average weight of one tuber.

When growing potatoes for any purpose, fractional composition is always of great importance. In accordance with the international standard GOST - 33996-2016 — "Seed potatoes" are standard mini tubers with a size of 9-60 $\mathrm{mm}$ in the transverse smallest diameter $[2,14,15]$. The analysis of the fractional composition of the Kolomba variety is presented in table 4 .

Table 4. Determination of fractional composition.

\begin{tabular}{|c|c|c|c|c|c|c|}
\hline Faction & $\begin{array}{c}\text { "Young" plants } \\
\text { (control) }\end{array}$ & $\%$ & "Old" plants & $\%$ & Micro-tubers & No. \\
\hline$<9$ & 2 & 13 & 19 & 3 & 14 & 11 \\
\hline $10-20$ & 12 & 24 & 34 & 12 & 38 & 32 \\
\hline $20-30$ & 26 & 28 & 40 & 28 & 32 & 27 \\
\hline $30-40$ & 44 & 31 & 44 & 47 & 26 & 22 \\
\hline $40-50$ & 9 & 4 & 6 & 10 & 8 & 8 \\
\hline$>50$ & 0 & 0 & 0 & 0 & 0 & 0 \\
\hline Total: & $\mathbf{9 3}$ & $\mathbf{1 0 0}$ & $\mathbf{1 4 3}$ & $\mathbf{1 0 0}$ & $\mathbf{1 1 8}$ & $\mathbf{1 0 0}$ \\
\hline
\end{tabular}

The results of studies showed that the cultivation of mini tubers using different source material allows to provide fairly high rates of quantitative standard fraction output within $87-98 \%$. In the structure of mini tubers' harvest, the small fraction (less than $9 \mathrm{~mm}$ ) in the option with "young" plants as the source material was only $2 \%$. Micro-tubers provided an output of the standard fraction of $88 \%$, "old" plants $-87 \%$.

\section{Conclusions}

The main goal in the production of mini tubers is to obtain the maximum number of healthy standard tubers from a single plant.

In our experiment, this indicator was recorded the highest in options where the source material was micro-plants planted at the end of the growth declining phase and microtubers, which also provided high output of standard fraction.

\section{References}

1. S.A. Banadysev, Potato seed production: organization, methods, technologies, (2003)

2. GOST 33996-2016 Seed potatoes. Technical conditions and methods of quality determination

3. M.Yu. Karpukhin, V.A. Dunin, M.L. Yusupov, I.N. Krupsky, E.M. Yushkin, Production technology of original, elite, and reproductive seed potatoes in the Middle Urals (2019)

4. Z.A. Marzoev, I.S. Kardanova, B.V. Anisimov, Potato Culture in Russia (analytical review) 33, (2019)

5. New technologies to produce revitalized source material in elite potato seed production (Recommendations), (2000)

6. E.V. Oves, B.V. Anisimov, A.I. Uskov, E.A. Simakov, S.V. Zhevora, V.V. Boyko, N.A. Gaitova, N.A. Fenina, I.V. Schmyglya, Guidelines for replication the material in vitro for original seed production of potatoes, 25 (2017) 
7. E.V. Oves, O.S. Kolesova, N.A. Gaitova, V.V. Boyko, N.A. Fenina, Formation of tubers in containers under various modifications of the nutrient medium

8. E.A. Simakova, B.V. Anisimov, E.V. Oves, Potato varietal resources for cultivation in the regions of Russia (reference edition), (2018)

9. S. Filippova, L. Eliseeva, O. Isaev, T. Ivanova, I Eliseev, L. Shashkarov, N. Malov, IOP Conf. Series: Earth and Environmental Science 604, 012038 (2020)

10. S. Filippova, L. Eliseeva, I. Eliseev, O. Nesterova, A. Selivanov, AGRITECH-IV-2020 IOP Conf. Series: Earth and Environmental Science 677, 032058 (2021)

11. S. Filippova, L. Eliseeva, E. Turbina, M. Prokopyeva, A. Selivanov, AGRITECH-IV2020 IOP Conf. Series: Earth and Environmental Science 677, 042048 (2021)

12. L. Shashkarov, G. Mefodiev, L. Eliseeva, S. Filippova, A. Selivanov, E. Turbina, AGRITECH-IV-2020 IOP Conf. Series: Earth and Environmental Science 677022091 (2021)

13. M.Yu. Karpukhin, F. Keita, International scientific-practical conference "Development of agro-industrial complex in the conditions of robotization and digitalization of production in Russia and abroad" (DAIC 2020), 222 (2020) https://doi.org/10.1051/e3sconf/202022203022

14. M.Yu. Karpukhin, F. Keita, International scientific-practical conference "Development of agro-industrial complex in the conditions of robotization and digitalization of production in Russia and abroad" (DAIC 2020), 222 (2020) https://doi.org/10.1051/e3sconf/202022203023

15. F. Keita, M.Yu. Karpukhin, Agrarian Bulletin of the Urals, Special issue "Biology and biotechnologies", 35-39 (2020) DOI: 10.32417/1997-4868- 2021-14-35-39. 